1Fundação Oswaldo Cruz (Fiocruz), Escola Nacional de Saúde Pública Sergio Arouca (Ensp) - Rio de Janeiro (RJ), Brasil. nmoyses@globo.com

2 Universidade do Estado do Rio de Janeiro (Ueri) Rio de Janeiro (RJ), Brasil.

\section{Especialização em Gestão do Trabalho e da Educação na Saúde: uma análise do programa nacional}

\author{
Specialization in Work Management and Health Education: an \\ analysis of the national program
}

Neuza Maria Nogueira Moysés', Ana Luiza Stiebler Vieira1, Tereza Cristina Guimarães', Andréa Lanzillotti Cardoso 2

DOI: $10.1590 / 0103-1104202012617$

RESUMO Um dos propósitos do Componente III do Programa de Qualificação e Estruturação da Gestão do Trabalho e da Educação no SUS (ProgeSUS) foi o de oferecer cursos de Especialização em Gestão do Trabalho e da Educação na Saúde. Nesse sentido, o objetivo deste estudo foi o de analisar tal processo formativo no País, discutindo seus resultados e as perspectivas analíticas dos dirigentes nos diferentes níveis de coordenação a partir de análise qualitativa e quantitativa. Assim, valeu-se de registros da coordenação geral e da aplicação de questionário semiestruturado do qual se extraiu a análise sob a ótica dos coordenadores locais. No total, foram qualificados 1.471 gestores, sendo 557 no Nordeste, 301 no Norte, 236 no Sudeste, 224 no Centro-Oeste e 153 no Sul. Constatou-se a grande permanência dos alunos nos cargos de gestão; a aplicabilidade dos projetos de intervenção por eles elaborados; o eixo Gestão do Trabalho de maior evidência nas duas primeiras turmas, mas de igual interesse com a Gestão da Educação na terceira turma; e a necessidade de aprofundamento e aumento de carga horária em temas específicos nesses eixos. Essas informações constituem importantes subsídios para a formulação de políticas públicas que deem continuidade a esse processo de qualificação principalmente em vista da crescente terceirização dos vínculos dos trabalhadores da saúde e da gestão dos trabalhadores do SUS.

PALAVRAS-CHAVE Mão de obra em saúde. Gestão em saúde. Educação em saúde.

\begin{abstract}
One of the purposes of component III of the SUS Work and Education Management Structuring and Qualification Program (ProgeSUS) was to offer specialization courses in Work Management and Health Education. The objective was to analyze this formative process in the country, punctuating its results and the analytical perspectives of the leaders at the different levels of coordination; from qualiquantitative analysis. It used records of the general coordination and the application of a semi-structured questionnaire in which the analysis was subtracted from the perspective of local coordinators. In total, 1,471 managers were qualified: 557 in the Northeast, 301 in the North, 236 in the Southeast, 224 in the Midwest and 153 in the South. It was verified: great permanence of the students in the management positions; applicability of the intervention projects prepared by them; the Labor Management axis of greater evidence in the first two classes, but of equal interest with the Education Management in the third class; and requiring deepening and increasing workload on specific topics in these axes. This information constitutes important subsidies for the formulation of public policies for the continuation of this qualification process, mainly due to the growing outsourcing of health workers 'labor relations and SUS workers' management.
\end{abstract}

KEYWORDS Health workforce. Health management. Health education. 


\section{Introdução}

Pesquisas realizadas pelo Conselho Nacional de Secretários de Saúde (Conass) em parceria com a Escola Nacional de Saúde Pública Sergio Arouca da Fundação Oswaldo Cruz (Ensp/Fiocruz) ${ }^{\mathbf{1}}$ e o Instituto de Medicina Social (IMS) da Universidade do Estado do Rio de Janeiro (Uerj) ${ }^{2}$, aduziram para a imperiosa necessidade de estruturar, reestruturar e qualificar a gestão dos Recursos Humanos (RH) em saúde nos estados e municípios brasileiros. Ampliando o olhar, os trabalhadores da saúde são vistos em seus processos de trabalho, no escopo e complexidade do setor e do mundo do trabalho e, em especial, os gestores de $\mathrm{RH}$, como importantes protagonistas. Progressivamente o conceito de 'recursos humanos' foi substituído pelo de 'força de trabalho' se aproximando da ciência política e dos fenômenos intrínsecos ao mercado de trabalho vigente.

Essa leitura oportunizou avanço importante na política de gestão de trabalho no Sistema Único de Saúde (SUS), culminando com a organização, no âmbito do Ministério da Saúde, da Secretaria de Gestão do Trabalho e da Educação na Saúde (SGTES). O Departamento de Gestão e da Regulação do Trabalho em Saúde (Degerts) é parte integrante e tornou-se o responsável nacionalmente, pela proposição de incentivos, acompanhamento e elaboração de políticas de gestão, planejamento e regulação do trabalho em saúde. Essa secretaria construiu em parceria com o Conass, o Conselho Nacional de Secretários Municipais de Saúde (Conasems), universidades, escolas de saúde pública, movimento sindical e conselhos profissionais, um novo arcabouço organizacional para a gestão do trabalho no SUS 3 .

Nessa estrutura, o Programa de Qualificação e Estruturação da Gestão do Trabalho e da Educação no SUS (ProgeSUS) foi instituído pelo Ministério da Saúde por meio da Portaria $\mathrm{n}^{\mathrm{o}} 2.261$, de 22 de setembro de $2006^{4}$, abrangendo quatro componentes: I- Estruturação da Gestão do Trabalho e Educação no SUS via apoio financeiro para instituição formal do setor, definição de equipe e estrutura física e a aquisição de equipamentos; II- Sistema de Informação Gerencial para o setor; IIIQualificação da Equipe de Gestão do Trabalho e da Educação no SUS, via capacitações para gestão por meio de cursos de atualização, especialização e mestrado profissional; e IVSistema Nacional de Informações em Gestão do Trabalho do SUS (InforSUS). A adesão foi livre por parte de estados e municípios, posteriormente foi requerido o cumprimento de um conjunto de requisitos e de acordos de adesão pública por meio de portarias publicadas no Diário Oficial da União.

Nacionalmente, os Cursos de Especialização de Gestores do Trabalho e da Educação na Saúde, parte do Componente III, foram coordenados pela Ensp/Fiocruz. Vale ressaltar que houve parcerias em todo o País com mais de vinte instituições acadêmicas tais como universidades federais, estaduais e escolas de saúde pública, além da adesão das secretarias de saúde.

A escolha para a coordenação nacional baseou-se na experiência do Núcleo de Estudos e Pesquisas em Recursos Humanos (NERHUS) do Departamento de Administração e Planejamento em Saúde (Daps/Ensp) tendo em conta sua tradição na formação de quadros para a área. Desde os anos 1980, o NERHUS acumulou expertise nessa formação por meio da oferta anual dos cursos de Capacitação em Desenvolvimento de Recursos Humanos de Saúde (CADRHU), transformado posteriormente para Curso de Especialização em Desenvolvimento de Recursos Humanos (CEDRHU), também ofertado de forma contínua e descentralizada. Ademais, modelou os cursos internacionais ou o Curso Internacional de Especialização em Gestão de Políticas de Recursos Humanos na Saúde (CIRHUS) para os países das regiões Andina e Mercosul e os estados brasileiros fronteiriços.

Dessa forma e embora tenha também participado do mestrado profissional, o NERHUS/Ensp modelou os objetivos, a 
proposta pedagógica e a estrutura do Curso de Especialização em Gestão do Trabalho e da Educação na Saúde em acordo com o Ministério da Saúde, com financiamento e direção da SGTES, em especial, do Degerts.

Tais cursos objetivaram dotar as instituições de saúde do SUS de quadros gerenciais qualificados capazes de administrar e desenvolver a área de gestão do trabalho e educação em saúde frente às suas especificidades e às crescentes complexidades institucionais. Suas atribuições eram as de analisar criticamente a reforma do setor saúde, suas implicações e responsabilidades para a gestão do trabalho e da educação na saúde; compreender a relação das políticas institucionais de qualificação da força de trabalho com a eficiência e efetividade dos serviços públicos de saúde; apoiar os serviços de gestão do trabalho das diferentes esferas gestoras na utilização dos sistemas de informação necessários ao planejamento e monitoramento da força de trabalho em saúde.

Tinha ainda, por atribuição identificar as diferentes formas de gestão dos vínculos de trabalho no SUS; identificar estratégias de integração entre as diferentes estruturas organizacionais de RH com as demais instâncias do SUS; e conhecer os desenhos organizacionais, analisando suas respostas aos diferentes desafios para uma efetiva organização, modernização e profissionalização da gestão do trabalho e da educação na saúde.

As turmas eram formadas com até 40 alunos selecionados dentre os indicados pelas instâncias gestoras do SUS, cujas exigências eram a escolaridade de nível superior completo e a atuação ou preparo para atuar na área de gestão do trabalho e da educação em suas instituições de origem, quer estaduais ou municipais.

A problematização foi a principal estratégia pedagógica do curso, estruturado em três unidades temáticas: 1- Políticas Públicas e Gestão do Trabalho e da Educação na Saúde (48h/aula); 2- Gestão da Educação na Saúde (96h/aula); e 3- Gestão do Trabalho na Saúde (96h/aula). Contemplou também o Trabalho de Campo (120h) e 40h de Seminário de Apresentação dos Trabalhos de Conclusão de Curso (TCC). A partir de 2013, na segunda etapa de estadualização dos cursos, a primeira unidade passou para $68 \mathrm{~h} /$ aula, a segunda para 104h/aula e a terceira para 132h/aula. Durante o período de dispersão entre as unidades, os trabalhos de campo se desenvolveram por meio de exercícios de enlace sob a orientação e acompanhamento da coordenação local do curso, de caráter avaliativo.

Sua principal finalidade foi a de identificar problemas de gestão do trabalho ou da educação na saúde, alvos de construção do TCC. O TCC tinha caráter obrigatório e deveria ser primordial e preferencialmente apresentado pelos alunos/gestores no formato de uma proposta de intervenção, considerada de melhor retorno para o enfrentamento de problemas identificados e de interesse das instituições de origem.

Houve ainda a opção de apresentação de artigo ou monografia, dependendo da origem institucional do aluno e das regulações das instituições acadêmicas parceiras aderentes ao ProgeSUS, particularmente quando se responsabilizavam pela emissão do título de especialista.

O curso, aqui resumidamente apresentado, pode ser conhecido no seu todo, assim como seu processo de operacionalização no País, em um capítulo de livro 'Qualificação da Gestão no Sistema Único de Saúde: a especialização de gestores do trabalho e da educação no contexto do cuidado'5.

Tendo em vista a dimensão do programa atribuído à Ensp, objetivou-se analisar esse processo formativo no País, analisando seus resultados e também as perspectivas analíticas dos protagonistas dirigentes nos diferentes níveis de coordenação.

\section{Material e métodos}

A análise descritiva do estudo transcorreu apoiada nas abordagens quantitativas 
e qualitativas, as quais, segundo Minayo ${ }^{6}$, diferenciadas pela sua natureza e pela sua utilidade, não se excluem, ao contrário, se complementam.

Para auxiliar a análise do processo nacional de formação, levantaram-se, na coordenação geral, os dados atualizados de todos os egressos por estados e regiões. A análise sob a ótica dos coordenadores locais estaduais foi extraída por meio da aplicação de questionário de 17 perguntas, das quais sete abertas, em cada estado que aderiu ao curso. Enviaram-se 36 questionários, com 92\% de resposta. Nas dez perguntas fechadas, os respondentes tiveram que escolher entre as opções 'ruim', 'regular', 'bom', 'muito bom', 'ótimo' e 'não posso avaliar'. Quatro blocos de questões se referenciaram às disciplinas ministradas, aos locais de realização dos cursos, ao corpo docente, e aos projetos de intervenção apresentados.

Especificamente, a intenção foi a de conhecer a percepção dos coordenadores locais quanto ao corpo docente, as disciplinas disponibilizadas, seus conteúdos, carga horária, referências bibliográficas, infraestrutura dos locais onde ocorreram os cursos, contribuição dos cursos na vida laboral dos alunos, e impacto na própria percepção dos coordenadores quanto à gestão do trabalho e da educação na saúde.

O estudo foi aprovado pelo Comitê de Ética em Pesquisa da Escola Nacional de Saúde Pública Sergio Arouca, da Fundação Oswaldo Cruz, sob o CAAE $n^{\circ}$ 01041418.0.0000.5240. Não apresenta conflito de interesses e, para garantia do anonimato dos respondentes, não foram citados em seus relatos, tendo em vista sua pública e oficial nomeação para o cargo de coordenação nos estados.

\section{Resultados e discussão}

\section{Implantação nacional dos Cursos de Especialização em Gestão do Trabalho e da Educação na Saúde}

Durante o período de execução de todos os cursos no País, de 2006 a 2017 e elaboração do relatório final em 2018, formaram-se 1471 gestores. A execução dos cursos se deu em três etapas, a primeira com turmas regionais e as duas subsequentes, estaduais. Vale destacar que a Ensp ofertou, ainda, duas turmas de mestrado profissional com 50 concluintes, que, somados aos concluintes da Universidade do Vale do Itajaí, totalizaram 80 mestres na área. A implantação de processos de qualificação em nível de especialização e mestrado profissional abrangentes, induzida pela instância federal trouxe grande reformulação e melhorias para a área.

A especialização, ofertada em sua primeira etapa em formato nacional, foi implantada com três turmas regionais, sendo uma turma com alunos do Norte e do Centro-Oeste, realizada em Brasília; uma turma com alunos do Sul e do Sudeste, desenvolvida na Ensp; e outra no Nordeste, realizada na Fiocruz de Pernambuco. Nesse formato regional, foram formados 116 gestores de um total de 120 matriculados (2007/2008), cujos TCC foram compilados em um livro.

Ainda nessa primeira edição ofertada nos estados e municípios, mais de 60 técnicos foram atualizados em concomitância com os cursos de especialização. Essa última modalidade contemplou os temas legislação da educação em saúde, legislação do trabalho em saúde e informação e informática em saúde, e formou 20 alunos por tema. 
O resultado final da execução dos cursos de especialização no País está resumido na tabela 1. A estratégia de unir forças na ação de especializar e atualizar conteúdos com clientelas distintas, de forma concomitante, reforçou as qualificações locais, mas precisou ser revista em virtude de comprometer o processo pedagógico, segundo avaliação dos alunos.

Tabela 1. Número de egressos da especialização em Gestão do Trabalho e da Educação na Saúde por estados e regiões, 2006-2017

\begin{tabular}{|c|c|}
\hline Regiões/Estados & № de egressos \\
\hline Região Norte & 301 \\
\hline Acre & 62 \\
\hline Amapá & 30 \\
\hline Amazonas & 49 \\
\hline Pará & 77 \\
\hline Rondônia & 29 \\
\hline Roraima & 29 \\
\hline Tocantins & 25 \\
\hline Região Nordeste & 557 \\
\hline Alagoas & 74 \\
\hline Bahia & 68 \\
\hline Ceará & 110 \\
\hline Maranhão & 62 \\
\hline Paraíba & 46 \\
\hline Pernambuco & 57 \\
\hline Rio Grande do Norte & 49 \\
\hline Sergipe & 68 \\
\hline Piauí & 23 \\
\hline Região Sudeste & 236 \\
\hline Espírito Santo & 40 \\
\hline Minas Gerais & 69 \\
\hline Rio de Janeiro & 53 \\
\hline São Paulo & 74 \\
\hline Região Sul & 153 \\
\hline Paraná & 47 \\
\hline Rio Grande do Sul & 59 \\
\hline Santa Catarina & 47 \\
\hline Região Centro-Oeste & 224 \\
\hline Distrito Federal & 51 \\
\hline Goiás & 55 \\
\hline Mato Grosso & 71 \\
\hline Mato Grosso do Sul & 47 \\
\hline Total Geral & 1.471 \\
\hline
\end{tabular}


Depreende-se da tabela 1 que a região Nordeste, que é composta pelo maior número de estados, apresentou maior número de egressos (557), dentre os quais se destaca o estado do Ceará com 110 concluintes. O estado do Piauí formou apenas 23 gestores, porque não realizou o curso de especialização na primeira etapa estadual. Embora tenha aderido ao curso, um incêndio que destruiu as dependências da Secretaria de Estado de Saúde (SES) dias antes da data prevista para seu início (2011-2013) só permitiu que participasse da segunda etapa descentralizada (2015-2017).

Na região Norte, se formaram 301 gestores. O estado do Pará (77) e do Acre (62) apresentaram maior número de egressos. $\mathrm{O}$ estado do Tocantins titulou a menor quantidade de alunos (25), fato que se explica pela realização de somente uma turma no período 2015-2017, embora tenha aderido inicialmente à proposta, inviabilizada devido às constantes mudanças de gestores da SES. A menor participação dos estados do Amapá, Rondônia e Roraima deveu-se ao fato de não terem aderido à execução do curso de especialização de 2015-2017. Ressalta-se que a descontinuidade administrativa gerada pelas mudanças de gestão impactou negativamente na promoção de qualificação da região que mais necessita de aporte de qualificação profissional.

Já na região Sudeste, com um total de 236 formandos, destacam-se os estados de São Paulo (74) e Minas Gerais (69), restando ao Espírito Santo (40) e Rio de Janeiro (53) os piores resultados. Uma explicação pode ser o fato de haver na região a maior oferta de qualificação profissional em todos os níveis.

A região Centro-Oeste formou 224 gestores, com maior número para o estado de Mato Grosso (71), embora tenha havido distribuição praticamente equitativa nos outros estados e Distrito Federal.

A região Sul, por sua vez, foi a que menos formou especialistas, apenas 153, dos quais 59 no Rio Grande do Sul, 47 no Paraná e 47 em Santa Catarina. Mesmo sendo composto por apenas três estados, pode-se constatar um moderado desempenho no processo nacional de formação de gestores, considerando, ainda, que o estado de Santa Catarina formou uma turma de 40 especialistas com recursos próprios. Nota-se que essa região investiu, mesmo antes do ProgeSUS, em formação de gestores para o SUS e apresentou certa tradição no conceito de educação permanente.

Como panorama geral, viu-se que as mulheres predominaram em todas as turmas; as enfermeiras também predominaram, à exceção de São Paulo; e a média de idade dos alunos e gestores foi de 31 a 45 anos. Aqui se reforça a tese de que a saúde é feminina e que existem gestores maduros na execução de habilidades gestoras.

$\mathrm{Na}$ primeira etapa de formação, ou dos cursos regionais, a participação de alunos e gestores dos municípios de grande porte foi $69,5 \%$. Na segunda etapa, ou primeira etapa estadual, $22 \%$ dos egressos eram gestores de municípios do interior dos estados. Na terceira etapa, vigente até 2017 , a descentralização da formação alcançou $81 \%$, dada a participação de alunos provenientes das secretarias de saúde de municípios de médio e pequeno porte, quando se utilizou a estratégia itinerante dos cursos em alguns municípios dos estados. Analisa-se, também, o quanto se capilarizou o acesso ao curso, permitindo a formação de gestores qualificados em áreas remotas do País.

Ressalta-se o comprometimento do Conass e Conasems no transcorrer da proposta de qualificação da área e de seus gestores tanto no nível central como no municipal das secretarias de saúde dos estados e municípios, corroborando, também, a maior capilaridade dos alunos e gestores oriundos do interior.

\section{A avaliação dos coordenadores estaduais do Curso de Especialização em Gestão do Trabalho e da Educação na Saúde}

A avaliação das ementas foi apreciada como muito boa para a maioria (52\%) dos coordenadores, ótima para $42 \%$ e boa para $6,0 \%$. Adequação da carga horária à realidade de cada 
estado foi julgada pelos respondentes como muito boa (49\%), ótima (33\%) e boa (18\%). Já a pertinência e a atualização das referências bibliográficas, foram avaliadas como muito boa (40\%), boa (35\%), ótima (27\%) e regular (6\%).

Importante ressaltar que toda a proposta do curso, construída pela coordenação nacional, foi amplamente discutida com os diversos atores envolvidos; gestores estaduais e municipais, Conass e Conasems, gestores da área de $\mathrm{RH}$, e docentes e pesquisadores das universidades e das escolas de saúde pública parceiras. Nas Oficinas de Avaliação e Monitoramento, a coordenação nacional sanou problemas classificados pelos coordenadores relativos à atualização bibliográfica e aos caminhos a serem seguidos na seleção e na formação, respeitando as diferentes realidades locais. Para garantia de maior autonomia docente e reforço dos conteúdos temáticos, foram credenciados novos professores, inclusive os egressos do mestrado profissional. Essa ampla discussão da metodologia do curso repercutiu nas avaliações.

O eixo de maior contribuição para a confecção de TCC nas duas primeiras turmas foi a Gestão do Trabalho. E, na última turma, $34 \%$ dos respondentes indicaram a mesma proporção para Gestão da Educação e Gestão do Trabalho; $16 \%$ opinaram que os dois eixos se sobressaíram; $13 \%$ avaliaram que os três eixos tiveram a mesma relevância; e 3\% não avaliaram. Essas mudanças na influência dos eixos temáticos para o TCC espelharam a priorização das agendas políticas das distintas secretarias de saúde.

Sobre a possibilidade de inclusão de novos eixos, $40 \%$ consideraram Nenhuma Inclusão; 39\% elencaram a necessidade de Aprofundamento Temático nos conteúdos existentes; e $21 \%$ não responderam. Além da sugestão quanto ao aumento de carga horária em Metodologia de Pesquisa, justificada pela dificuldade dos alunos gestores de produzir seus trabalhos, há os que opinaram pelo Aprofundamento Temático do conteúdo do curso, destacando a Gestão do Trabalho e da Educação em Saúde.
Tais temas, em realidade, constituem o cerne dessa especialização. Para eles, foram sugeridos aumento de carga horária, acréscimo de outros conteúdos e ampliação da carga horária em temas específicos tais como orçamento, leis trabalhistas, vinculação e relações de trabalho, educação permanente, práticas integrativas, e doenças ocupacionais, particularmente a Síndrome de Burnout. Como o processo de execução dos cursos de especialização do ProgeSUS foi longo (2006-17), sua avaliação e monitoramento compartilhado, ocorrido em diversas fases, não manteve os mesmos atores por todo o período, razão pela qual nem sempre foram avaliados pelos que construíram as estratégias. Nesse âmbito, há que se destacar que o conjunto de transformações ocorrido na área de gestão do trabalho prevê a heterogeneidade de vínculos que provoca essa mudança de atores pelo tempo decorrido.

Em relação aos locais de realização dos cursos, a infraestrutura foi considerada ótima por $46 \%$ dos respondentes; $36 \%$ consideraram muito boa; e 18\%, boa. A influência dos locais para o desenvolvimento do curso foi considerada muito boa por $43 \%$; $27 \%$ a considerou ótima; $18 \%$, boa; $9 \%$ não se sentiram em condições de avaliar; e 3\% consideraram regular. Ressalta-se que a infraestrutura local do curso ficou sob a responsabilidade dos estados, do Conselho de Secretarias Municipais de Saúde (Cosems) e de instituições de ensino parceiras. Um dos critérios de avaliação para adesão ao curso foi a comprovação da existência de infraestrutura física, técnica e tecnológica para sua execução, o que justifica a ótima avaliação.

Relativamente ao corpo docente, perguntou-se se a relação entre professor e aluno favorecia o processo ensino e aprendizagem. A maioria (55\%) avaliou como ótima, seguida da opção muito boa (39\%) e boa (6\%). Quanto ao domínio dos docentes nas disciplinas, $75 \%$ avaliaram como ótimo; $19 \%$ como muito bom; e $6 \%$, bom. Se os docentes criaram um ambiente de discussão e interação em sala de aula, $70 \%$ avaliam como ótimo; $27 \%$, muito bom; e 3\%, bom. 
Sobre o desempenho dos docentes em trabalhar com alunos e gestores, a maior parte dos respondentes avaliou como ótimo (64\%); 30\% considerou muito bom; e 6\%, bom. A adequação dos docentes à aplicação de metodologias ativas de ensino, $49 \%$ avaliou como muito bom; $30 \%$, ótimo; e $21 \%$; bom. Os cursos de especialização foram se constituindo e fortalecendo ao longo da formação dos docentes. Muitos estados qualificaram previamente os docentes por meio de oficinas de alinhamento de seus conteúdos e expertises aos objetivos previstos na formação, sendo os melhores quadros designados para tal atividade.

Quanto às Metodologias Ativas, a coordenação geral elencou diversas opções, mas vale ressaltar que necessitavam de ampliação da carga-horária e ocupação de maiores espaços físicos para dinâmicas e divisão de grupos. Muitas vezes, tais espaços não foram disponibilizados, embora os docentes mais experientes tenham habilmente feito uso das ferramentas.

Na implantação do TCC sob o formato de um de projeto de intervenção, apresentaram-se como pontos desfavoráveis para os alunos e gestores as mudanças na gestão e a grande rotatividade dos espaços laborais. Destacam-se as alternâncias de gestão como uma interferência na efetivação dos produtos oferecidos pelo curso.

Quanto à contribuição do curso para a ascensão e mobilidade laboral, $52 \%$ dos respondentes afirmaram que os egressos continuaram em cargos de gestão, como assessoria de gabinete, coordenação de unidade básica de saúde, gestor municipal de saúde, entre outros; $24 \%$ dos ex-alunos têm se empenhado em ocupar cargos de gestão ou articulação política junto aos gestores. Entretanto, $21 \%$ dos respondentes não soube informar quanto à contribuição do curso para a mobilidade laboral, pelo não acompanhamento dos egressos nas secretarias e dinamismo das mudanças políticas nos municípios; e, ainda, $3 \%$ afirmaram que, com as mudanças de gestão, os egressos não continuaram gestores ou trocaram de função.

A permanência em cargos de gestão pela maioria dos egressos constitui um fator bastante positivo, possibilitando a aplicação das habilidades apreendidas, embora sem garantias em razão das mudanças nos cenários políticos estaduais e municipais. Ao longo desse processo de formação, os municípios menores se tornaram mais presentes, mesmo com a menor oportunidade de participação, dados os custos de deslocamento e a liberação dos servidores.

Ademais, 24\% dos coordenadores responderam que houve aprovação dos ex-alunos em concursos para cargos públicos e admissão em mestrados; $24 \%$ relataram ascensão de cargos; $15 \%$ afirmaram tanto aprovação em concursos públicos quanto ascensão de cargos; 34\% não souberam responder; e 3\% não responderam. Em caso de continuidade dessa formação, será necessário um estudo sobre o perfil dos egressos.

Sobre o desafio dos respondentes de coordenar um novo curso com as mesmas características, $91 \%$ responderam positivamente; $6 \%$ relataram inserção em outro projeto educacional, impossibilitando retorno como coordenador; e 3\% disseram depender da ocasião em que esses novos cursos aconteceriam.

A grande maioria enalteceu a vivência do curso em si, seus objetivos e o impacto causado por ele nas secretarias de saúde e na vida profissional dos envolvidos. Destacamos os relatos de alguns deles:

Coordenar o Curso de Especialização em Gestão do Trabalho e da Educação na Saúde do ProgeSUS foi uma experiência de crescimento e desenvolvimento profissional, considerando minha atuação enquanto servidora da Fundação Oswaldo Cruz. Eu aceitaria sim, com enorme prazer, coordenar um novo curso com essas características, inclusive em um outro estado da federação. Consideraria isto uma oportunidade de contribuir com a formação dos gestores da saúde e continuar ampliando o conhecimento sobre a realidade brasileira, algo que valorizo bastante.

Com certeza, foi uma experiência relevante para minha carreira profissional. 
Certamente, tendo em vista o aprendizado e contribuição com o sistema de saúde municipal e estadual.

Sim, com certeza e cabe ressaltar que agora sou professora da Universidade Integração Latinoamericana e este tipo de curso poderia contar com profissionais gestores de saúde dos países do Mercosul ou da América Latina e Caribe. Acredito que o impacto no nível de integração seria muito relevante e contribuiria com a internacionalização da formação em saúde.

Para ser um coordenador dos cursos do ProgeSUS, foi requerido o aprimoramento de habilidades, desde a capacidade de organizar os aspectos administrativos, conteúdos e docentes, itens metodológicos, negociação do trabalho institucional e extrainstitucional, até a capacidade de síntese permanente para garantir a transversalidade dos temas, pois o coordenador deveria ficar em sala de aula todo o tempo, até a orientação e correção dos exercícios de enlace e na coorientação dos TCC. Isso revela uma oportunidade significativa de aprimoramento diferenciado.

Ao questionar se o curso despertou interesse no coordenador em contribuir para a área de gestão de trabalho, caso ele não atuasse na área, $46 \%$ responderam que despertou o interesse, e uma das respondentes revela que:

Com certeza, hoje meu olhar é bem mais ampliado para a área de gestão do trabalho e quando participo de comissões ou em discussões, eu sempre tento incluir a gestão do trabalho e mostrar a sua importância, pois entendo ser essa uma área essencial para o SUS.

Dos respondentes, 36\% relataram que já atuaram na área e aproveitaram para se aprofundar em determinados temas, como a exemplo de:

Já sou da área e fui muito motivada a investir em temas que não domino dentro da própria área, com debates muito qualificados com os especialistas do curso.
Deve-se ter em conta que coordenar um processo de qualificação na mesma área de formação é o melhor que se poderia construir. Quando se aprofundam os conhecimentos do ponto de vista teórico e de investigação, fortalece-se e aumenta-se a capacidade gestora. Dentre o restante dos respondentes, $3 \%$ informaram que já atuaram na área, mas que então estavam se dedicando à docência, $\mathrm{e}$ $15 \%$ não responderam. Mesmo que atuando na docência, acredita-se que esses profissionais contribuam com o reforço da área, principalmente na formação das profissões da saúde.

\section{Considerações finais}

A mudança na política de Gestão de Recursos Humanos no Ministério da Saúde com a criação da SGTES e seus dois departamentos, Degerts e Departamento de Gestão da Educação na Saúde (Deges), inaugurou um novo momento para a área sob a perspectiva da gestão do trabalho e da educação em saúde. A qualificação de gestores, que tradicionalmente era disponibilizada nas capitais, foi descentralizada, possibilitando o acesso à especialização para um contingente expressivo de gestores de municípios de médio e pequeno portes.

Cabe destacar que a estratégia de construir parcerias em todo o país com instituições acadêmicas e escolas de saúde pública foi uma inovação necessária para a superação do desafio de encurtar as grandes distâncias e, também, uma rica experiência com suas participações no planejamento, execução, docência, avaliação e, em alguns casos, na certificação da titulação. $\mathrm{O}$ número de especialistas formados na área fala por si só. Há, claramente, um corte e substituição da ausência de técnicos qualificados em grandes extensões do território nacional para a afirmação de que em todos os 26 estados e o distrito federal hoje existem profissionais qualificados para o exercício da gestão do trabalho e da educação em saúde, fortalecendo a capacidade gestora desses entes federados. 
Relativamente à avaliação dos coordenadores, embora as premissas presentes no edital de adesão dos estados ao curso e as construções de caráter metodológico e pedagógico tenham sido discutidas e acordadas previamente, uma pequena parcela dos coordenadores locais não qualificou a ementa, carga horária e infraestrutura como ótimas ou muito boa. A necessidade de oficinas para repactuação da direção dos cursos, respeitando as realidades locais, indicou, para numa próxima capacitação nesses moldes, a necessidade de prévia preparação pedagógica dos coordenadores em todos os cursos.

A Gestão do Trabalho foi o eixo de maior evidência nas duas primeiras turmas e apresentou o mesmo interesse que Gestão da Educação na terceira turma. De um modo geral, foi requerido um aprofundamento temático ou aumento de carga horária em temas específicos nesses dois eixos. O corpo docente foi muito bem avaliado e, quando encorajados a praticar metodologias ativas, os mais experientes fizeram uso dessas ferramentas.

Mesmo com mudanças de gestão nas secretarias de saúde, evidenciou-se que o curso contribuiu para a ascensão e mobilidade ocupacional da maioria dos ex-alunos, assim como a permanência em cargos de gestão após o curso, favorecendo, sobremaneira, municípios de menor porte.

A aplicabilidade de projetos de intervenção como o TCC guardou relação com a permanência no cargo de gestão. A maioria dos respondentes aceitaria o desafio de coordenar um novo curso com as mesmas características e, também, mostrou interesse em contribuir com a área de gestão do trabalho e da educação em saúde, mesmo os coordenadores que ainda não faziam parte da área.
Essas informações, análises e proposições constituem subsídios estratégicos para a formulação de políticas públicas para a continuidade e organização de processos de qualificação. Requer, ainda, uma investigação sobre os egressos para o aprofundamento analítico de todo esse esforço formativo.

Cabe ressaltar que a dificuldade na realização do curso pôde ser sentida à medida em que houve necessidade de pactuação local com as coordenações, e de cada uma delas com suas expectativas quanto ao curso e poder aleatório de gerenciamento em suas localidades. O maior desafio foi o de qualificar força de trabalho tão heterogênea e de realidades tão díspares, observando adequações pertinentes quanto à abordagem e material didático.

Não obstante, as pesquisas ${ }^{\mathbf{1}, \mathbf{2}}$ que indicaram o que precisava ser feito para área de $\mathrm{RH}$ à época, foram retomadas dez anos depois ${ }^{7} \mathrm{e}$ as realidades locais já apresentavam mudanças significativas. A gestão do trabalho estava mais estruturada no âmbito das secretarias, e seus gestores, mais qualificados e alinhados às políticas pertinentes.

Mas, levando em consideração que a saúde é expansiva e que, hodiernamente, os trabalhadores da saúde estão altamente terceirizados, tornam-se imperiosas a continuidade e expansão da qualificação da gestão do trabalho e da educação na saúde.

\section{Colaboradoras}

Moysés NMN (0000-0001-6441-8906)*, Vieira ALS (0000-0002-6282-1723)*, Guimarães TC (0000-0002-9620-6024)* e Cardoso AL (0000-0003-4306-7355)* contribuíram igualmente para a elaboração do manuscrito. 


\section{Referências}

1. Conselho Nacional de Secretários de Saúde. Estruturação da área de recursos humanos nas Secretarias de Saúde dos Estados e do Distrito Federal. Brasília, DF: CONASS; 2004. (Documenta, N. 1).

2. Universidade Estadual do Rio de Janeiro, Instituto de Medicina Social. Relatório Técnico: Capacidade Gestora de Recursos Humanos em instâncias locais de saúde em municípios com população superior a 100 mil habitantes. Rio de Janeiro: Observatório de Recursos Humanos em Saúde (ObservaRH), 2006. [acesso em 2019 set 16]. Disponível em: http://www. observarh.org.br/observarh/repertorio/Repertorio_ ObservaRH/IMS-UERJ/Capacidade_gestora.pdf.

3. Moysés NMN. Gestão do trabalho no Sistema Único de Saúde: a agenda política postergada? [tese]. Rio de Janeiro: Escola Nacional de Saúde Pública Sergio Arouca, Fundação Oswaldo Cruz; 2015. 121 p.

4. Brasil. Ministério da Saúde. Portaria $\mathrm{n}^{0} 2.261$, de 22 de setembro de 2006. Institui o Programa de Qualificação e Estruturação da Gestão do Trabalho e da Educação no SUS - ProgeSUS. Diário Oficial da União. 26 Set 2006. [acesso em 2020 jun 29]. Disponível em: http://bvsms.saude.gov.br/bvs/saudelegis/gm/2006/ prt2261_22_09_2006_rep_comp.html.
5. Moysés NMN, Tavares MFL, Guimarães TCF, et al. Qualificação da Gestão no Sistema Único de Saúde: a especialização de gestores do trabalho e da educação no contexto do cuidado. In: Castilho Sá M, Tavares MF, Seta MH, organizadoras. Organização do Cuidado e Práticas em Saúde: abordagens, pesquisas e experiências de ensino. Rio de Janeiro: Fiocruz; 2018. p. $431-453$.

6. Minayo MCS. O desafio do conhecimento: Pesquisa Qualitativa em Saúde. 12. ed. São Paulo: Hucitec-Abrasco; 2010.

7. Conselho Nacional de Secretários de Saúde. $2^{\circ}$ Levantamento da Organização, Estrutura e Ações da Área de Recursos Humanos das Secretarias Estaduais de Saúde. Brasília, DF: CONASS; 2015. (CONASS documenta, N. 29).

Recebido em 23/01/2020

Aprovado em 07/06/2020

Conflito de interesses: inexistente

Suporte financeiro: não houve 